\title{
The Perceived Threat of SARS and its Impact on Precautionary Actions and Adverse Consequences: A Qualitative Study Among Chinese Communities in the United Kingdom and the Netherlands
}

\author{
Xinyi Jiang • Gillian Elam • Cicely Yuen • \\ Helene Voeten • Onno de Zwart • Irene Veldhuijzen • \\ Johannes Brug
}

Published online: 19 February 2009

(C) International Society of Behavioral Medicine 2009

\begin{abstract}
Background Although the SARS outbreak involved few probable cases of infection in Europe, swift international spread of infections raised the possibility of outbreaks. In particular, SARS presented a sociopsychological and economic threat to European Chinese communities because of their close links with the outbreak's origins.

Methods A qualitative study was conducted among Chinese residents in the United Kingdom and the Netherlands to identify the origins of SARS risk perceptions and their impact on
\end{abstract}

\footnotetext{
X. Jiang $\cdot$ G. Elam

Health Protection Agency-Centre for Infections,

London, UK

X. Jiang

College of Art, Science \& Engineering,

University of Dundee,

Dundee, UK

C. Yuen $\cdot$ O. de Zwart $\cdot$ I. Veldhuijzen

Municipal Public Health Service Rotterdam Area,

Rotterdam, the Netherlands
}

H. Voeten $\cdot$ O. de Zwart $\cdot$ J. Brug

Department of Public Health,

Erasmus MC University Medical Center,

Rotterdam, the Netherlands

J. Brug

EMGO Institute VU University Medical Center,

Amsterdam, the Netherlands

\section{Jiang $(\triangle)$}

Queen Mother Building,

University of Dundee,

Dundee DD1 4HN, UK

e-mail: x.y.jiang@dundee.ac.uk precautionary actions and adverse consequences from the perspective of vulnerable communities living in unaffected regions. Analysis was informed by protection motivation theory. Results Results revealed that information from affected Asia influenced risk perceptions and protective behavior among the Chinese in Europe when more relevant local information was absent. When high risk perceptions were combined with low efficacy regarding precautionary measures, avoidancebased precautionary action appeared to dominate responses to SARS. These actions may have contributed to the adverse impacts of SARS on the communities.

Conclusions Experiences of European Chinese communities suggest that practical and timely information, and consistent implementation of protective measures from central governments are essential to protect vulnerable populations in unaffected regions from unnecessary alarm and harm during outbreaks of emerging infections.

Keywords Severe acute respiratory syndrome (SARS) . Chinese population $\cdot$ Risk perceptions - Precautionary behavior . Qualitative $\cdot$ Protection motivation theory

\section{Introduction}

The epidemic of severe acute respiratory syndrome (SARS) resulted in few probable cases of infection in Europe-four of which were reported in the United Kingdom (UK), all of whom recovered; no cases were reported in the Netherlands [1]. Its swift international spread, however, indicated a very real possibility of outbreaks in Europe. This threat was associated with international air travel with about $80 \%$ of reports of possible SARS infections in Europe originating 
from individuals that had traveled from China, Hong Kong, Taiwan, Singapore, and Vietnam [2].

For European Chinese communities, SARS was a threat in terms of potential infection through contact with people from affected countries and stigmatization derived from perceived association with the outbreak's origins. A cross-sectional survey among Chinese and non-Chinese Rotterdam residents revealed that, during the SARS outbreak, respondents from the Chinese population were more likely to be worried about the risk of SARS infection, have high risk perceptions, and take precautionary measures compared to the non-Chinese population (de Zwart, personal communication). During the outbreak, economic losses were observed in the community following a drop in travel and tourism to affected Asia and reduced tourism and business in European Chinatowns (Thomas Chan, personal communication).

The significance of SARS for the European Chinese is underlined by their existing vulnerability in accessing health information and services. Small in numbers and dispersed in settlement patterns determined by the nature of their catering trade, the Chinese population in Europe is less visible and harder to target compared to other minority ethnic populations [3]. For example, the Health Survey for England (HSE) reports that, compared to other major ethnic groups, Chinese men and women are less likely to access general health care services [4]. The reasons for such differences in healthseeking behavior, however, are not available from the HSE.

Understanding how individuals experience and respond to health risks can be derived from the protection motivation theory [5-9]. This theory posits that information about a health threat evokes two cognitive processes: the formation of risk perceptions and appliance of protective behavior. The formation of risk perceptions is a process of "threat appraisal" of perceived severity and the likelihood of threat to the individual-both need to be elevated for a high risk perception to occur. Only those with a high risk perception will take precautionary actions but individuals need to believe such actions are effective (response efficacy) and that they are personally able to undertake such actions (self-efficacy). Information-seeking about a risk's severity and vulnerability is an essential part of this process $[10,11]$. Intentions to implement protective actions, however, can be weakened by the perceived costs of the advocated risk-reducing behavior and the perceived benefits of the risk-enhancing behavior. As a consequence, people with high response efficacy could have low selfefficacy and would not adopt protective behavior.

In Europe, SARS-related public health information tended to focus on travel. Member states issued regularly updated travel advice warning against travel to specific areas with ongoing transmission. For example, such warnings were issued from the UK's Health Protection Agency (HPA), Department of Health (DH), Foreign and Commonwealth
Office, the Netherlands' Community Health Service (GGD), and Ministry of Public Health, Welfare and Sport. Despite efforts to reach Chinese communities, such as providing bilingual information on websites (e.g., HPA and GGD) and sending leaflets to the communities (e.g., DH), these outputs were produced relatively late during the epidemic.

To date, most studies about risk communication and sociopsychological impacts of SARS have centered on affected Asia and Canada. These studies indicate that public fear of SARS had a major psychological impact among populations in affected Asia [12], Canada, and the unaffected United States (US) [13]. Discrimination towards SARS patients and perceived carriers occurred in affected Asia [12, 14, 15]; Canada's Chinese communities [16] and Japan's Chinese students [17] reported negative experiences during the SARS period. BBC News [18] and The Age [19] reported economic loss from SARS in the UK and the US. The World Health Organization (WHO) [20] yearly report devotes a whole chapter on SARS, but mainly regarding the affected regions. However, little is known about its impacts on vulnerable communities in unaffected countries, and the interactions between information-seeking and perceptions of severity, vulnerability, and efficacy that underpin SARSrelated risk perceptions and precautionary actions.

This study aimed to examine SARS-related risk perceptions and their impacts on precautionary actions and adverse consequences from the perspective of vulnerable communities living in unaffected regions. In addition, the study sought to investigate Chinese communities' information sources and the factors that influenced their risk perceptions and use of precautionary actions, and to further understand the adverse consequences of emerging infections for vulnerable communities. The study results will inform public health interventions in unaffected countries to protect ethnic minority populations with close links to the origins of future outbreaks.

\section{Methods}

Qualitative methods were used in this study to investigate perceptions, attitudes, behavior, knowledge, beliefs, and experiences [21]. Data were collected in focus group discussions (FGDs) during which open questioning was employed to encourage participants to provide detailed descriptions along with interactive follow-up probes to seek explanations, clarification, and comparison. A group facilitator ensured that the discussion was participatory and interactive. Archive press cuttings and video clips stimulated recall.

In total, 164 Chinese residents, community and business representatives participated in 23 FGDs in nine cities with significant Chinese populations in the UK (London, Manchester, Glasgow, Belfast, and Cardiff) and the Netherlands (Rotterdam, Amsterdam, Utrecht, and Arnhem) between 
October 2005 and April 2006. Participants from different segments of the Chinese population were recruited from sites frequented by the resident Chinese in partnership with community representatives and supplemented by snowballing contacts from selected participants. A purposive sample design ensured diversity in background and attitude by setting recruitment targets for sex, age, first language, country of origin (mainland China, Hong Kong, or others), duration of residence in Europe, and occupation (Table 1).

Table 1 Demographic background of FGD participants in the UK and the Netherlands

\begin{tabular}{|c|c|c|c|c|}
\hline & & \multicolumn{3}{|c|}{ Number of respondents } \\
\hline & & Male & Female & Total \\
\hline \multirow[t]{6}{*}{ Age (years) } & $18-24$ & 8 & 12 & 20 \\
\hline & $25-34$ & 16 & 22 & 38 \\
\hline & $35-44$ & 10 & 16 & 26 \\
\hline & $45-54$ & 26 & 21 & 47 \\
\hline & $55+$ & 16 & 14 & 30 \\
\hline & Missing data & 1 & 2 & 3 \\
\hline \multirow[t]{9}{*}{ Region } & London & 18 & 12 & 30 \\
\hline & Manchester & 9 & 20 & 29 \\
\hline & Belfast & 10 & 6 & 16 \\
\hline & Glasgow & 6 & 13 & 19 \\
\hline & Cardiff & 0 & 5 & 5 \\
\hline & Rotterdam & 11 & 11 & 22 \\
\hline & Amsterdam & 7 & 10 & 17 \\
\hline & Utrecht & 10 & 0 & 10 \\
\hline & Arnhem & 6 & 10 & 16 \\
\hline \multirow[t]{3}{*}{ Spoken languages } & $\begin{array}{l}\text { English/Dutch } \\
\text { and Cantonese }\end{array}$ & 19 & 24 & 43 \\
\hline & Mandarin & 24 & 33 & 57 \\
\hline & Cantonese & 34 & 30 & 64 \\
\hline \multirow[t]{3}{*}{ Origin } & Hong Kong & 44 & 46 & 90 \\
\hline & Mainland China & 27 & 30 & 57 \\
\hline & Other & 6 & 11 & 17 \\
\hline \multirow{4}{*}{$\begin{array}{l}\text { Length of residency } \\
\text { in Europe }\end{array}$} & UK/Netherlands born & 7 & 10 & 17 \\
\hline & 5 years or more & 53 & 62 & 115 \\
\hline & Less than 5 years & 17 & 13 & 30 \\
\hline & Missing data & 0 & 2 & 2 \\
\hline \multirow[t]{7}{*}{ Occupation } & $\begin{array}{l}\text { Catering/import/ } \\
\text { tourism }\end{array}$ & 33 & 25 & 58 \\
\hline & Community work & 12 & 14 & 26 \\
\hline & Health-related & 7 & 8 & 15 \\
\hline & Student & 7 & 11 & 18 \\
\hline & Retired & 9 & 0 & 9 \\
\hline & Housewife & 0 & 14 & 14 \\
\hline & Other & 9 & 15 & 24 \\
\hline \multicolumn{2}{|l|}{ Total number } & 77 & 87 & 164 \\
\hline
\end{tabular}

Facilitator-led discussions were conducted in Mandarin, Cantonese, and English with the aid of a topic guide developed for use in both study regions. Between four and ten people took part in each discussion, which lasted between $1 \frac{1}{2}$ to 2 hours. The topic guide structured a list of topics for the discussions. The guide ensured that, in each study site, key topic areas required to generate data relevant to the main research questions were consistently covered, but also permitted the introduction of new ideas and insights from participants. Respondents were invited to describe their impressions of SARS, attitudes towards and experiences of SARS-related information sources, their perceptions of risk severity and vulnerability, precautionary actions undertaken, and impacts of SARS on their business, work, social and family lives, and psychological state, including fears and worries at the time. Participants were encouraged to suggest appropriate and feasible measures they wished governments to implement in response to future emerging infections. All discussions were audio-recorded and transcribed into English.

The verbatim data were analyzed thematically using Framework, a matrix-based technique informed by grounded theory [21]. Summaries from the verbatim data were organized under thematic headings derived from the topic guide, discussion content, and protection motivation theory. Data under each heading were then coded and categorized to produce descriptions of the attitudes and behaviors present in the population. The data were then further interrogated and compared to produce interpretations and explanations grounded in participants' experiences, knowledge, and perceptions.

\section{Results}

The study results include data on information-seeking during the outbreak and its impacts on risk perceptions. Other factors informing risk perceptions and perceived efficacy of precautionary actions, the range of precautionary actions adopted during the outbreak, and adverse impacts of SARS, are also presented.

Information-Seeking and Risk Perceptions

Sources that participants recalled using during the outbreak were diverse in format (television, newspapers/magazines, Internet, and interpersonal communication), language (Chinese, English, and Dutch), source (news media, public health authorities, health workers, families, and friends), geographic origin (Asia, UK/Netherlands, Canada, and the US), and coverage (international, national, and regional). Sources of information that used Chinese languages, were in-depth, updated, and demonstrated proximity to the outbreak were preferred by most respondents. These sources included major 
Chinese language media (newspapers published in Europe, satellite TV, and popular Internet news websites based in China and elsewhere), public health agency websites for affected regions (such as Hong Kong's Department of Health), and interpersonal and familial social networks. Although the initial cover-up of the outbreak in mainland Chinese media caused panic among communities, a drastic improvement of coverage and measures boosted confidence in this source, in particular sources from the regions of China that people originated from. Major local European language media (TV, newspapers, and Internet news websites) and websites of health authorities such as WHO were used by English/Dutch-speaking respondents.

Nevertheless, mass media coverage of SARS from and about both affected Asia and unaffected Europe was regarded as exaggerated and sensational. Respondents expressing this view recalled that images of orientallooking people wearing face masks dominated both Asian and local European mass media, which initiated a feeling of fear. Different focuses in media coverage were noted and an impression of a racialized discourse in European media was recalled. For example, the Asian media were associated with regularly updated death and infection bulletin tolls, implementation of protective measures, and the sacrifices made by the health workers. Memories of European media coverage focused on travel warnings, alarmist predications about the global spread, and blame on the Chinese government's handling of the outbreak. Awareness of information available from British and Dutch public health organizations was low among the group participants. Lack of information in Chinese languages from these sources was identified as a reason for using communications intended for infected regions, for example, WHO and Hong Kong's Department of Health websites, rather than local public health agencies. Such a perceived gap was described as:

"I wanted to know the situation [of SARS infection] in the UK. What I knew was the situation in Hong Kong. The British media kept reporting how many people died in Hong Kong or in China. But they didn't report what had happened here." (Manchester Mandarin)

The combined coverage of SARS in Asia and Europe informed the belief that SARS was a serious health threat because it was portrayed as incurable, fatal, mysterious (with no known origin or cure), highly transmissible, and quick to develop.

"I think in the case of SARS it's so quick, you could be affected in the morning and die in the afternoon, so there is no way you can have a hope..." (Glasgow Cantonese)

The focus in the media on how SARS originated in a hotel elevator in Hong Kong and spread locally and globally by air flight informed the view that a similar spread could happen in Europe. Such views were described as adding to a sense of proximity to SARS and vulnerability. Local community gossip about people rumored to be infected or recently returned from affected regions further fuelled anxiety about proximity to potential carriers. Participants recalling such vulnerability remembered their need for reassurance at the time of the outbreak, but felt that there was a lack of precautionary guidance in European media and from local public health authorities.

Media reports demonstrating that SARS had a lower death toll in general or compared to flu or traffic accidents contributed to lower risk perceptions, but such reports appeared mainly during the end of the epidemic.

"Common flu infects more people and causes more death than SARS does!" (Glasgow Mandarin)

"... the death rate was not really all that high among the infected, so I was not really that worried." (London Mandarin)

Friends and families living in affected regions on the whole provided reassurance that people in affected regions were not at high risk of SARS or dying. These were in contrast to negative mass media coverage and were said to have contributed to lower risk perceptions. For example, this participant preferred the direct reports he received from his family living in an affected region indicating that the situation was not as bad as was portrayed in the media:

"They [family in affected regions] knew ... what was happening in the actual place. [When] we heard it from media, it was a different [worse] story ... They can actually tell you the positive news." (Glasgow Cantonese)

\section{Factors Informing Risk Perceptions}

In addition to media reports and personal communication, participants' descriptions of their risk perceptions and the reasons for them included references to environmental factors and location, level of faith in government measures, the amount of daily, unfamiliar contacts in social networks, and spiritual beliefs and culture. Table 2 summarizes the range of factors that participants referred to in their explanations of their risk perceptions. In this table, factors that were mentioned as explanations for higher or lower seriousness or vulnerability at the time of the SARS outbreak are grouped together.

\section{Low Risk Perceptions}

Lower risk perceptions were influenced by the knowledge that cases of SARS had not been confirmed locally in Europe and the view that the prospect of a local outbreak was low due to the geographical distance of Europe from infected 
Table 2 Factors reported during the FGDs that informed perceptions of risk of SARS infection

\begin{tabular}{lll}
\hline Perceptions of ... & \multicolumn{1}{l}{ Factors described in relation to specific risk perceptions } \\
\cline { 2 - 3 } & Low risk perceptions & High risk perceptions \\
\hline $\begin{array}{l}\text { Seriousness of SARS } \\
\text { infection }\end{array}$ & $\begin{array}{l}\text { Reassurance from people living in affected } \\
\text { regions; } \\
\text { Believe the SARS death rate to be lower } \\
\text { than that for flu. }\end{array}$ & Believe that infection leads to death; \\
$\begin{array}{l}\text { Vulnerability to SARS } \\
\text { infection }\end{array}$ & $\begin{array}{l}\text { Living environment seen as safe; } \\
\text { Confidence in state measures; } \\
\text { Spiritual beliefs. }\end{array}$ & $\begin{array}{l}\text { Daily contact with unfamiliar people or with people suspected as } \\
\text { coming from infected regions. }\end{array}$ \\
\hline
\end{tabular}

Asian regions. In addition, the environment in Europe was regarded as less prone to the spread of infectious diseases due to the presence of less-crowded living conditions, greater hygiene, and cooler climate compared to Asia.

"SARS is affecting the tropical regions only ... I knew that [the] Netherlands is cooler; we have different temperature, so I think the risk is lower." (Utrecht Cantonese)

Respondents that had lower levels of social contacts and lived in smaller towns with fewer tourists and Chinese also felt less threatened by SARS.

"Compared to big cities such as London or Manchester, the chance of catching SARS in my town was very slim.” (Manchester Mandarin)

Optimism regarding local outbreaks was strengthened by confidence in government prevention systems in case of an outbreak and trust in the effectiveness of enforced precautionary measures such as port controls and quarantine.

"People came from Hong Kong had health check, so I was not worried." (London Mandarin)

Accounts of lower risk perceptions also referred to cultural and religious beliefs, fatalism, as well as the attitude that life should not be hampered because of fear of SARS along with European acculturation and higher priorities such as work and study.

"People die everyday.” (London Mandarin)

"Destiny decides everything" ... "If God puts me as risk, I will be at risk." (Manchester Mandarin)

"You need to still live your life, don't you?" (Manchester British born Chinese)

\section{High Risk Perceptions}

Higher risk perceptions were informed by the association of infection with death and scientific uncertainty regarding the cause of SARS. In particular, people working in environments that involved prolonged contact with tourists and unfamiliar members of the Chinese public, for example, restaurant and community workers, felt at increased risk of infection.

"As we are running Chinese restaurants, it's impossible not to contact the customers. When they approached us, we had no idea if they had SARS or not. It made us worry about the prevention measures that could be taken." (Arnhem Mandarin)

Factors Informing Efficacy of Precautionary Measures

Table 3 summarizes the different factors contributing to levels of either response efficacy or self-efficacy. Participants' accounts describing examples of low response efficacy referred to the lack of general information about SARS, absent or conflicting information about protective behavior in Europe, and evidence that measures such as port controls and self-imposed quarantines were inconsistently applied in the UK and the Netherlands. Surprise was expressed at the lack of entry checks in the UK on return from Hong Kong.

"I personally think they could've done a lot more with people coming into the country because I just walked straight through, no checks. I just heard all the news there that it was so bad in Hong Kong and I was just thinking when I was coming back how they weren't doing a lot about this? I came in here so easy." (Manchester British born Chinese)

Explanations for higher perceptions of response efficacy, on the other hand, referred to measures adopted in affected Asia. For example, measures including quarantine, isolation, contact tracing, closure of schools and public places, port controls, temperature monitoring, wearing face masks, avoiding crowded public places, and hygienic measures, were believed by respondents to be in place and effective. 
Table 3 Factors reported during the FGDs that informed perceived efficacy of precautions

\begin{tabular}{lll}
\hline & Low efficacy & High efficacy \\
\hline Response efficacy & $\begin{array}{l}\text { Lack of knowledge about precautions; } \\
\text { Conflicting advice on precautions; } \\
\text { Inconsistent implementation of measures. }\end{array}$ & $\begin{array}{l}\text { Positive images, e.g., health workers wearing face masks; } \\
\text { Knowledge of measures in affected regions and at ports; } \\
\text { Confidence in information from media/authorities/family. }\end{array}$ \\
& $\begin{array}{l}\text { Peer/crowd variance in behavior; } \\
\text { Concern about public reactions/harm to relationships; }\end{array}$ & $\begin{array}{l}\text { Shared peer/crowd actions; } \\
\text { Experience of using measures in affected regions; } \\
\text { Ease of uptake, e.g., canceling trips, avoiding crowds, hygiene; }\end{array}$ \\
& Absent guidance; & Existing knowledge of flu control. \\
\hline
\end{tabular}

Some of these measures, for instance, port controls, were believed to be implemented in Europe. Measures such as wearing masks and avoiding the crowded places were regarded as effective because of their history of providing protection from respiratory infections.

Peer pressure appeared to have contributed to levels of self-efficacy. Respondents reported they were unlikely to wear a face mask if nobody else was seen to wear it. They were more likely to believe in the value of avoidance-based strategies following friends and families' advice or under community pressure. Some respondents reported high response efficacy but low self-efficacy if precautionary actions were associated with adverse outcomes. For example, although some believed that wearing a face mask could be an effective precaution, concerns were expressed about attracting discrimination because face masks might indicate infection in the wearer. Similarly, avoiding visitors or returned families and friends was considered to be harmful to relationships. Therefore, although masks were stored by some respondents, they were mainly worn on visits to affected regions and during flights. Self-efficacy was also informed by levels of ease in implementing the behavior. Lower efficacy was caused by difficulties obtaining face masks or maintaining strict quarantine, whereas canceling or postponing trips to infected regions was regarded feasible.

\section{Range of Adopted Precautionary Actions}

The precautions respondents recalled being undertaken during the outbreak are summarized in Table 4. Precautions based on avoidance of possible carriers dominated respondents' accounts. Most commonly, these strategies took the form of avoiding Chinese gathering places where visitors and returnees from affected regions were thought likely to be.

"We avoided Chinese places because Chinese come back and forth. You don't even know who had been back, they may have brought back some germs." (Glasgow Cantonese)
Some respondents, however, avoided any gathering place, particularly enclosed spaces with restricted air circulation such as theaters, casinos, or London's underground.

"No matter they are Chinese or Westerners, they all travel around world today, especially the business people." (Cardiff Mandarin)

Relatives and friends from affected regions were also avoided.

“... we had a lot of relatives and friends who came to visit the UK. I was really scared when they came because I remember the time when SARS was around, my sister-in-law came to the UK and I wouldn't go near her for two weeks I think. They say that the period is two week isn't it to let them settle in? I was really scared; I just wanted to stay away from her." (Manchester British born Chinese)

Despite some awareness that 2 weeks would be an effective quarantine period, quarantine was practiced partially or inconsistently. Some respondents described withdrawing voluntarily from work or social contacts for a few days on return to Europe; others had to be told to stay away. Some returned boarding school students stayed in bed and breakfast accommodation, whereas others stayed at home, but mixed with other householders. Some were unaware of quarantine practices, which caused community tension. Additional precautionary actions recalled by respondents included hygiene (for example, hand washing), avoiding people with coughs, and healthy living to improve their ability to fight diseases.

\section{Adverse Impacts of SARS}

Respondents reported that SARS had adverse economic, social, and psychological impacts on their communities. As a result of the popularity of avoidance strategies as a precautionary measure, respondents reported Chinatowns in major cities experienced a drop in numbers of tourists and 
Table 4 Precautionary behaviors reported during the SARS outbreak

\begin{tabular}{ll}
$\begin{array}{l}\text { Avoidance-based } \\
\text { behavior }\end{array}$ & $\begin{array}{l}\text { Delay/cancel travel to infected regions; } \\
\text { Avoid gathering places or prolonged exposure to them, e.g., restaurants, sedentary community activities, crowds/tourists, } \\
\text { Chinatown; } \\
\text { Quarantine on return from affected regions; } \\
\text { Avoid visitors/returnees from affected regions. }\end{array}$ \\
Wearing face masks & $\begin{array}{l}\text { Worn on visits to affected regions/during flights; } \\
\text { Obtained and stored for future use/sent by relatives; } \\
\text { Not worn in UK/Netherlands due to fear of creating suspicion. }\end{array}$ \\
Reaction to symptoms & $\begin{array}{l}\text { Advise staff with coughs to stay at home and/or to seek medical advice; } \\
\text { Cautious of Chinese people coughing and wearing masks. }\end{array}$ \\
Healthy living & $\begin{array}{l}\text { Eat well; } \\
\text { Hygiene measures, e.g., hand washing. }\end{array}$ \\
\hline
\end{tabular}

local British/Dutch and Chinese customers. Attendance decreased in some Chinese community centers. Travel agencies specializing in Far-east Asian regions reported trade loss. Some respondents reported that they had lost their jobs because of reduced business.

"It made me unemployed. My Chinese restaurant couldn't continue ... it used to receive tourists mainly." (Amsterdam Cantonese)

Community tensions were fuelled by rumors that some community center staff or users were infected with SARS or had failed to conduct self-quarantine on return from affected regions. Similar tensions between residents and visitors/returnees were reported.

“There were Chinese who didn't observe this [quarantine] rule and wandered around. The result was that ... if someone had come back from Asia, he would have found himself excluded by other Chinese." (Manchester Mandarin)

A major psychological impact was indicated by reports of emotional anxiety about families in affected regions and when making trips to affected regions. Anxiety appeared to be related to fear of infection and the consequences of precautionary measures.

"It was said that quarantine was prevalently practiced in China. What if when we had been back [to China] and had been quarantined? Then we wouldn't have been able to get out. Both my child's schooling and my own study would have been affected. I found it really terrifying; so I thought it better to get the flight tickets cancelled.” (Cardiff Mandarin)

The sight of any mask wearers was considered "scary."

"... one of the girls that had just come back, she wore a mask ... and the other pupils were so scared because they thought she had to wear a mask so she must have some sort of virus or germs." (Glasgow community representatives)

Some respondents felt discriminated against, particularly because of the way local residents linked SARS with Chinese people.

"Since I'm Chinese some of my classmates asked: 'How's your country? Why did this happen?' I even encountered some unpleasant foreigners on streets, they would ... 'ke ke ke' [imitating coughing] and gave the hint that I was ill. It wasn't pleasant..." (Manchester Mandarin)

\section{Discussion}

The study findings exemplify the impacts of an outbreak of an emerging infection on vulnerable communities living in unaffected regions. Our research supports that global information sources, especially those with sensational and racialized tendencies, were influential in the levels of vulnerability perceived among communities originating from affected regions. In the absence of timely, locally relevant, and practical guidance, precautionary advice intended for affected regions appeared to be absorbed by these communities. Furthermore, the group discussion data gave indications that the relationship between efficacy and behavior was mediated by expectations of stigmatizing social consequences that precautionary actions such as wearing face masks might attract. These factors led to the adoption of avoidancebased risk reduction strategies that may have contributed to the adverse economic, social, and psychological impacts on Chinese communities in Europe during the SARS outbreak. 
Respondent's perceptions that the mass media coverage of SARS in Europe was sensational and racialized are supported by findings from media content analyses. Studies reveal that mass media in Western countries tended to portray SARS in terms of the seriousness of the disease and use a "threat" theme that was negatively contextualized with China and the Chinese [16, 22-25], thus contributing to public fear about China, Chinatowns, and the Chinese presence in public. The experiences recalled by our respondents support the conclusions of other studies that suggest information originating from sites associated with the location of the outbreak where ethnic communities had close links is important in forming risk perceptions and the nature of precautionary actions [16]. This suggests that greater coordination with global media providers is required in the production of risk communications. Production of communications intended for unaffected regions needs to acknowledge that these communications might be undermined by seemingly conflicting information from affected regions that might be absorbed by migrant communities.

Participants' accounts indicate that the perceived efficacy of precautionary actions was sometimes based on inaccurate perceptions, for example, the belief that screening tests were in place at European ports of entry. Similar beliefs have been reported in previous studies [26]. Behavioral responses are likely to change when perceived efficacy is based on misconceptions. When correct information comes to light, behavior is reviewed.

The study findings demonstrate that people's intentions to protect themselves are weakened by the perceived social costs of possible precautions. Moreover, our study suggests that, in the process of appraising threats and appropriate behavior, Chinese values, cultural environments, religious or life attitudes, and personal circumstances can play a role in different perceptions and coping styles. Similar conclusions were drawn which suggest that such factors helped to explain the differences in preventive behaviors of the Chinese during SARS [27, 28]. Our study findings regarding efficacy correspond with the results of the survey of Chinese residents [29] that confirm low levels of selfefficacy and response efficacy in this group when compared to the general population in affected regions that took part in the international survey [30]. It further indicates that, for potentially effective measures to be implemented, risk communications need to be grounded in social norms.

The special needs of vulnerable communities were acknowledged by the European Commission [31] which was reported to have provided information during the outbreak "adapted to the local culture through a multiplicity of media and distribution means" and implemented via the "rapid and effective response of national health authorities across Europe." However, the experiences of Chinese communities in the UK and the Netherlands imply that appropriate and timely information was largely unavailable during the early stages of the outbreak, despite efforts made by a string of organizations. This study demonstrates that even if the Chinese population are prone to lower risk perceptions compared to the general British and Dutch populations, as the survey revealed [29] but due to the nature of such data, unable to explain, information needs will still be high and harmful behavior can occur. More importantly, in the absence of credible information from relevant authoritative sources, less relevant sources such as rumor and gossip will be used to fill the knowledge gap, as Kapferer [32] and Sjöberg [33] pointed out. Our findings indicate that clear guidance and consistent implementation of protective measures from central governments is essential to prevent unnecessary, inappropriate, and even harmful behavior taken by the communities.

This study was conducted retrospectively over 2 years after the outbreak of SARS which might have affected the accuracy of the data as our study relied on people's memories and recall of beliefs and attitudes at the time of the outbreak. In addition, the transience and mobility of the Chinese population meant that some key informants might have moved on since SARS. However, close links formed with key informants and purposive recruitment ensured inclusion of respondents with diverse SARS experiences. Media reports produced at the time of the outbreak were available for respondents to aid recall and group facilitation techniques were effective in seeking clarity and identifying uncertainty.

These study findings are relevant for other ethnic communities and outbreaks of infectious diseases in their countries of origin. These communities will be vulnerable to infection and to discrimination. They will have heightened concerns regarding families living in affected regions. Furthermore, these communities will have their own information networks comprising community-specific media provided both in their country of origin and country of residence; and also through contact with people living in affected regions.

The study findings indicate the importance of protecting vulnerable ethnic minority populations who might suffer from neglect even in states with an advanced public health protection system. More importantly, despite the challenges of communicating risk to ethnic minority populations who use diverse global information sources, a coordinated response from global media and national authorities will be essential. At a minimum, authorities in unaffected areas need to be able to communicate with information providers outside their own countries of jurisdiction and not rely on national outlets alone, as these will not reach population subgroups that regularly access media from their home countries. Similarly, broadcasts from affected regions need to acknowledge that they are likely to have an audience 
from unaffected regions who are also seeking advice and guidance. Accurate, timely, and transparent provision of information is critical for containing the outbreak and reducing public fear and uncertainty in response to new and emerging infections such as SARS in a global scope, not only in affected regions. In order to minimize adverse effects on vulnerable populations in unaffected regions during future outbreaks, needs assessment is required to map out the scope and nature of potential threats (physical, economic, and sociopsychological) and to assess the communication channels responsible for contributing to both risk perceptions and perceived efficacy of precautionary actions.

Acknowledgements We thank all participants who contributed to the project and the community organizations for their support including: Chinese National Health Living Centre (London), "Wai Yin" Chinese Women Society (Manchester), Chinese Welfare Association (Belfast), Chinese Healthy Living Centre (Glasgow), "San Jai" Chinese Project (Glasgow), Chinese Association "Wah Fook Wui" (Rotterdam), Chinese Church EMSI (Utrecht), Ruian Education Foundation (Arnhem), Chinese Women Association (Arnhem), Chinese Women Association "Ho Tin" (Amsterdam), Chinese School "Wah Yan" (Rotterdam), Chinese Temple "Ho Wah Chi" (Amsterdam), EMSI "Rotterdam Youth Fellowship" (Rotterdam). Advice was provided by Lord Michael Chan MBE-Member House of Lords and Chair of Chinese in Britain Forum; Thomas Chan-Chair of the Chinese Takeaway Association and Director of the Chinese in Britain Forum; Lorraine Lighton-Greater Manchester Health Protection Unit; Dr. Yimmy Chow; Prof Angus Nicholl; and colleagues at the HPA-CfI Respiratory Diseases Department. Sadly Lord Chan, one of the instigators of this study, died in early 2006.

\section{References}

1. World Health Organization. Severe acute respiratory syndrome: cumulative number of reported probable cases of SARS, from 1 Nov 2002 to 11 July 2003. http://www.who.int/csr/sars/country/ 2003_07_11/en/index.html (2003, July 11). Accessed 8 August 2006.

2. EU Communicable Diseases Network. Cumulative number of SARS cases detected in the EU, EFTA, and candidate countries from 24 February to 23 July 2003. http:/europa.eu.int/comm/ health/ph_threats/com/sars/sars_stats_en.htm (2003, July 23). Accessed 30 August 2003.

3. Jiang X. Fujianese migration on the margin: a study of migration culture through history, media representation and ethnography. Unpublished doctoral dissertation, Cardiff University, UK; 2006.

4. Sproston K, Pitson L, Whitfield G, Walker E. Health and lifestyles of the Chinese population in England. London: Health Education Authority; 2001.

5. Rogers RW. A protection motivation theory of fear appeals and attitude change. J Psychol. 1975;91:93-114. (September).

6. Rogers RW. Cognitive and physiological process in fear appeals and attitude change: a revised theory of protection motivation. In: Cacioppo J, Petty R, editors. Social psychophysiology. New York: Guilford; 1983. p. 153-76.

7. Maddux JE, Rogers RW. Protection motivation theory and selfefficacy: a revised theory of fear appeals and attitude change. J Exp Soc Psychol. 1983;19:469-79.
8. Prentice-Dunn S, Rogers RW. Protection motivation theory and preventive health: beyond the health belief model. Health Educ Res. 1986;1(3):153-61.

9. Rogers RW, Prentice-Dunn S. Protection motivation theory. In: Gochman DS, editor. Handbook of health behaviour and research I: personal and social determinants. New York: Plenum; 1997. p. 113-32.

10. Tanner JF, Hunt JB, Eppright DR. The protection motivation model: a normative model for fear appeals. J Mark. 1991;55:3645.

11. Eppright DR, Tanner JF, Hunt JB. Knowledge and the ordered protection motivation model: tools for preventing AIDS. J Bus Res. 1994;22(1):55-69.

12. Leung K. Editorial: psychology of severe acute respiratory syndrome (SARS). Asian J Soc Psychol. 2004;7.

13. Blendon RJ, Benson JM, DesRoches CM, Raleigh E, TaylorClark K. The public's response to severe acute respiratory syndrome in Toronto and the United States. Clin Infect Dis. 2004;38:925-31.

14. Lee S, Chan LYY, Chau AMY, Kwok KPS, Kleinman A. The experience of SARS-related stigma at Amoy Gardens. Soc Sci Med. 2005;61:2038-46.

15. Ko CH, Yen CF, Yen JY, Yang MJ. Psychological impact among the public of the severe acute respiratory syndrome epidemic in Taiwan. Psychiatry Clin Neurosci. 2006;60:397-403.

16. Leung C, Guan J. Yellow peril revisited: impact of SARS on the Chinese and Southeast Asian Canadian Communities. http://www. ccnc.ca (2004). Accessed 4 June 2006.

17. Zheng G, Jimba M, Wakai S. Exploratory study on psychosocial impact of the severe acute respiratory syndrome (SARS) outbreak on Chinese students living in Japan. Asia-Pac J Public Health. 2005;17(2):124-9.

18. BBC News. War and SARS hit hotel group. http://news.bbc.co.uk/ 1/hi/business/3102954.stm (2003, September 12). Accessed 20 November 2005.

19. The Age. US economy feels effect of SARS. http://www.theage. com.au/articles/2003/04/24/1050777335035.html (2003, April 24). Accessed 20 November 2005.

20. World Health Organization. Chapter five: SARS: lessons from a new disease. In The World Health Report 2003-shaping the future. http://www.who.int/whr/2003/chapter5/en/index.html (2003). Accessed 4 June 2006.

21. Ritchie J, Lewis J, editors. Qualitative research practice. London: Sage; 2003.

22. Razum O, Becher H, Kapaun A, Junghanss T. SARS, lay epidemiology and fear. Lancet. 2003;361:1739-40.

23. Washer P. Representations of SARS in the British newspapers. Soc Sci Med. 2004;59:2561-71.

24. Huang Y, Leung CCM. Western-led press coverage of mainland China and Vietnam during the SARS crisis: reassessing the concept of 'media representation of other'. Asian J Commun. 2005;15(3):302-18.

25. Tian Y, Stewart CM. Framing the SARS crisis: a computerassisted text analysis of $\mathrm{CNN}$ and $\mathrm{BBC}$ online news reports of SARS. Asian J Commun. 2005;15(3):289-301.

26. Brug J, Aro AR, Oenema A, de Zwart O, Richardus JH, Bishop GO. SARS risk perception, knowledge, precautions, and information sources, The Netherlands. Emerg Infect Dis. 2003;8:1486-9.

27. Chang WC, Sivam R. Constant vigilance: heritage values and defensive pessimism in coping with severe acute respiratory syndrome in Singapore. Asian J Soc Psychol. 2004;7:35-53.

28. Ji L, Zhang Z, Usborne E, Guan Y. Optimism across cultures: in response to the severe acute respiratory syndrome outbreak. Asian J Soc Psychol. 2004;7:25-34.

29. Voeten HACM, de Zwart O, Veldhuijzen IK, Yuen C, Jiang X, Elam $\mathrm{G}$, et al. Risk perception and sources of information related to 
emerging infectious diseases such as SARS among Chinese communities in the UK and the Netherlands. Int J Behav Med. 2008;in press.

30. de Zwart O, Veldhuijzen IK, Elam G, Aro AR, Abraham T, Bishop GD, et al. Perceived threat, risk perception and efficacy beliefs related to SARS and other (emerging) infectious diseases: results of an international survey. Int J Behav Med. 2008;in press.

31. European Commission. Measures undertaken by member states and accession countries to control the outbreak of SARS. http://ec. europa.eu/health/ph_threats/com/sars/sars_measures_en.pdf (2003). Accessed 4 June 2006.

32. Kapferer JN. A mass poisoning rumor in Europe. Public Opin Q. 1989;53(4):467-81.

33. Sjöberg L. Attityder till svenskt medlemskap i EU och riskperception. Paper presented at a meeting organised by Styrelsen för psykologiskt försvar: "EU-medlemskap", Stockholm, September; 1994. 